\title{
A DESMISTIFICAÇÃO DOS ÁRABES E MUÇULMANOS ATRAVÉS DA TELEDRAMATURGIA BRASILEIRA: UM ESTUDO DA TELENOVELA $O$ CLONE
}

\author{
Jéfferson Balbino ${ }^{1}$
}

Resenha do Livro: PORTO, César Henrique de Queiroz. A Representação dos árabes e muçulmanos na televisão brasileira. 1. ed. Curitiba: Appris, 2020.

A telenovela tem uma importância transcendental para a cultura brasileira. No ar há quase $70 \operatorname{anos}^{2}$, o Brasil já se viu, por muitas vezes, representado nas inúmeras narrativas ficcionais produzidas e exibidas pelas emissoras brasileiras de televisão. Contudo, não foram apenas as telenovelas com enredos repletos de brasilidade que acompanhamos nesse longo período de teledramaturgia brasileira, haja vista que - dada a originalidade dos novelistas ${ }^{3}-$ também pudemos acompanhar tramas que trouxeram ao telespectador culturas e costumes de outros povos como, por exemplo, a telenovela $O$ Clone, de autoria de Glória Perez, produzida e exibida entre 2001 e 2002, pela TV Globo.

O Clone foi exibida no emblemático ano de 2001, marcado não apenas pelo início do século XXI, mas também pelos ataques terroristas contra os Estados Unidos, promovidos pela organização fundamentalista islâmica Al-Qaeda, liderada pelo saudita Osama Bin Laden. No dia 11 de setembro de 2001, os terroristas lançaram ataques suicidas - através de aeronaves contra os prédios do Pentágono, em Washington, e no World Trade Center (também conhecido como Torres Gêmeas), em Nova York, resultando na morte de mais de três mil pessoas. Foi nesse contexto histórico que vinte dias após o atentado terrorista, em 01 de outubro de 2001,

\footnotetext{
${ }^{1}$ Doutorando e Mestre em História. Universidade Estadual Paulista "Júlio de Mesquita Filho" - Campus Assis, Brasil. Bolsista CAPES. E-mail: jefferson.balbino@ unesp.br. ORCID: https://orcid.org/0000-0002-2516-5122.

${ }^{2}$ O gênero surgiu no país, em 1951, na extinta TV Tupi, com a telenovela Sua Vida me Pertence. Escrita por Walter Foster, a primeira telenovela da TV brasileira era exibida em 15 capítulos que foram "transmitidos apenas duas vezes por semana, as terças e quintas, às 20 horas". (BALBINO, 2016, p. 33).

${ }^{3}$ Termo utilizado par designar os autores e roteiristas de telenovelas no país.
} 
estreou a telenovela $O$ Clone, trazendo em sua espinha dorsal toda a cultura muçulmana, além de outros temas tabus como clonagem humana e dependência química.

Obviamente, que os atentados serviram para reforçar estereótipos preconceituosos em torno dos árabes e muçulmanos que, lamentavelmente, ainda são caracterizados por muitos como: terroristas, intolerantes religiosos que pregam a guerra e o ódio, misóginos e bígamos.

Como a telenovela, em especial às tramas exibidas no horário nobre da TV Globo, têm um grande alcance social, $O$ Clone ao trazer a representação dos muçulmanos para os lares brasileiros pôde desmistificar a maneira que esse povo era visto até então. E, é justamente a representação que essa telenovela trouxe dos árabes e muçulmanos que o pesquisador César Henrique de Queiroz Porto analisou em sua obra A Representação de Árabes e Muçulmanos na Televisão Brasileira, publicado em 2020, pela Appris Editora.

O livro A Representação de Árabes e Muçulmanos na Televisão Brasileira é composto por: uma apresentação escrita pelo próprio autor para situar sintetizadamente seu leitor; uma introdução, um prefácio escrito pelo professor e pesquisador Peter Demant; por quatro capítulos; pelas considerações finais; referências e índice remissivo. A obra é oriunda da tese de doutoramento de Porto, defendida em 2012 no Programa de Pós-Graduação em História Social, da USP.

Logo na introdução, Porto já esclarece o conceito "orientalidade", que ele cria para designar as representações simplificadas e caricaturadas da cultura arabo-islâmica que ocorre não só no Brasil, mas em todo o Ocidente. Também, na Introdução, o autor enfatiza o quão inexistente ainda são as pesquisas cientificas que envolvem a "reação televisiva ao mundo muçulmano", sobretudo, no campo da História. Porto, traz preciosos dados de como o Islã está no rol de pesquisas acadêmicas, tanto no Brasil como nos Estados Unidos, o que elucida, principalmente, que há poucos historiadores brasileiros que utilizam a televisão como objeto de estudo. (PORTO, 2020, pp. 23-26).

Em sua obra, César Porto - de modo didático - explicita a maneira como o historiador pode utilizar a telenovela e/ou fontes audiovisuais num trabalho historiográfico, inclusive, o mesmo demonstra dialogando com outros pesquisadores como, por exemplo, Marcos Napolitano, Maria Immacolata Vassalo Lopes e Maria de Lourdes Motta o produto telenovela como uma ação pedagógica explícita, essencialmente, por servir como documento histórico de uma época, além de um lugar de memória.

No primeiro capítulo, intitulado Televisão e Telenovela no Brasil, o autor traça teoricamente a inserção da televisão e da telenovela nas sociedades, perpassando pelas teorias da cultura de massa, o desenvolvimento da mídia, a Escola de Frankfurt e a Teoria Crítica Atual. 
Inclusive, é nesse capítulo que Porto tece uma contumaz explicação sobre os conceitos fundamentais em pesquisas com fontes audiovisuais, sendo eles: "experiência mediada" (a partir de John B. Thompson) e "experiência deslocalizada" (a partir de Milly Buonanno). Esses conceitos são esclarecedores para a compreensão das experiências que os telespectadores possuem com as representações teleficcionalizadas. Ainda nesse primeiro capítulo, além de fazer um retrospecto acerca da inserção da televisão no Brasil, desde seu surgimento até sua consolidação, Porto se propõe a analisar a estrutura da TV Globo, haja vista o fato da mesma ser a maior emissora de televisão do Brasil e a principal produtora de telenovela na América Latina.

Não obstante, o autor se apossa de Jesus Martin-Barbero e Paulo Freire para analisar o papel da televisão como mediadora da educação, visto que a TV também tem a possibilidade de educar. Inclusive, Porto corrobora da teoria de Maria de Lourdes Motta para defender a "Pedagogia da Telenovela", que serve para esclarecer assuntos relevantes do cotidiano atrelados aos enredos teledramatúrgicos. (PORTO, 2020, p. 91). Porto, também, dialoga com Benedict Anderson e seu conceito de "comunidades imaginadas" para demonstrar como a telenovela pode propor “a acepção de novos modos de estar juntos". (PORTO, 2020, p. 100).

No segundo capítulo, denominado Representações do Islã na Telenovela O Clone, César Porto se utiliza do escopo teórico de Carlo Ginzburg, Sandra Jatahy Pesavento, Francisco J. Calazans Falcon e Roger Chartier para elucidar e aplicar o conceito "representação", tão essencial nessa pesquisa. Conquanto, o presente capítulo também traz consigo informações pertinentes ao meio da televisão como, por exemplo, a medição da audiência através do IBOPE (Instituto Brasileiro de Opinião Pública e Estatística). Tal contextualização é essencial para dar uma unicidade ao texto de Porto, basta ver que a telenovela $O$ Clone foi um retumbante sucesso. Aliás, o número de (re) exibições da trama comprova este feito, pois além da exibição original entre 2001 e 2002, a telenovela esteve no ar em outras três ocasiões: em 2011, no Vale a Pena Ver de Novo; entre 2019 e 2020 no Canal Viva (TV a cabo); e, atualmente ${ }^{4}$, está novamente no ar na sessão de reprises vespertinas da TV Globo.

Um dos pontos altos, desse segundo capítulo, está quando Porto tece a seguinte menção explicativa a despeito da televisão como forma de expressão cultural:

A televisão como forma de expressão cultural inscrita na moderna tradição da cultura brasileira é um meio de representação. Uma novela pode representar algo, uma cultura, uma época, uma religião como o islã, por exemplo. Essa representação pode retratar uma realidade dada, percebida ou interpretada.

\footnotetext{
${ }^{4}$ A segunda reprise da telenovela $O$ Clone na sessão Vale a Pena Ver de Novo teve início em 04 de outubro de 2021, na TV Globo. A trama também está disponível na íntegra na plataforma de streaming Globoplay, desde outubro de 2020, sendo uma das 10 novelas mais vistas pelos assinantes.
} 
Também pode evocar um universo imaginário criado pelos autores, escritores, diretores e produtores da obra. A ficção, apesar do aspecto imaginativo, criativo, também permite a realização de uma leitura da realidade sóciohistórica. (PORTO, 2020, p. 138).

Essa reflexão do pesquisador é essencial, haja vista que situa o leitor sobre o modo como um produto, nesse caso a telenovela $O$ Clone, serve como um elemento sociocultural, sobretudo, por trazer para o grande público (que, em alguns casos, é composto por telespectadores que não possuem letramento a ponto de se informar por si próprio sobre determinado conteúdo abordado na ficção) informações relevantes sobre a cultura e os costumes de um determinado povo. Ou seja, a partir da telenovela é possível o telespectador obter informação e conhecimento. Contudo, como ressalva Porto, essa sapiência repassada através da ficção é filtrada pela ótica de quem a produz, isto é, podendo chegar ao telespectador de maneira deturpada e parcial.

A despeito das representações das personagens, o autor se vale a pesquisadora Maria de Lourdes Motta para esclarecer como $O$ Clone trouxe personagens calcadas na realidade, isto é, um recurso utilizado pela novelista Glória Perez - e outros autores de telenovelas - para aproximar a ficção da realidade vivenciada pelos telespectadores. Aliás, é esse recurso que - na visão de Porto - faz com que a narrativa ficcional obtenha credibilidade para cativar o público. (PORTO, 2020, p. 176). Ainda no presente capítulo, o historiador trata do conceito "diagnóstico crítico", de Douglas Kellner, para mostrar como a mídia convoca "textos, imagens, narrativas e ideologias" e como isso é traduzido dentro do campo midiático. (PORTO, 2020, p. 219).

No final do segundo capítulo e início do terceiro capítulo (intitulado: Ocidentalismo, conservadorismo e fundamentalismo na televisão brasileira), Porto problematiza a questão de gênero ao analisar, através das personagens femininas de $O$ Clone, como as mulheres estão inseridas - em espaços de sociabilidades - na cultura oriental. O autor ancora-se nos conceitos "estruturalismo", "fundamentalismo islâmico", "escrituralista" e "neofundamentalista" para explicar, já no terceiro capitulo, os discursos produzidos na referida telenovela ao perfil reacionário representado através de Tio Abdul (Sebastião Vasconcelos) que Porto, por sua vez, caracteriza-o sob a ótica dos conceitos "escrituralismo" e/ou do "neofundamentalismo", uma vez que a personagem em questão "se apresenta como puritano, literalista e que corporifica um passado mítico, idealizado, distantes”. (PORTO, 2020, p. 268). César Porto afirma - respaldado no filósofo estadunidense Douglas Kellner - que os produtos da cultura de mídia também podem revelar posicionamentos utópicos, subversivos e contestadores. E, nesse sentido, a telenovela $O$ Clone conseguiu abarcar tais posicionamentos, basta ver a maneira como 
promoveu na sociedade brasileira (que consumia esse produto midiático) um debate acerca da alteridade islâmica.

No quarto - e derradeiro - capítulo, As Mil e Uma Noites e a Orientalidade, o autor se detém a analisar como a obra traduzida por Antoine Galland (As Mil e Uma Noites) é importante para fomentar o imaginário ocidental sobre a cultura do Oriente. E, conseguintemente, até que ponto essa obra correlaciona com as representações do oriente islâmico presentes na telenovela $O$ Clone e - de modo geral - na televisão brasileira. Porto ainda demonstra como a representação orientalista e a mídia convergem à medida que é influenciada pela tradição literária orientalista da obra As Mil e Uma Noites. Aliás, é nesse capítulo, que o conceito "orientalidade" - elaborado por Porto - é amplamente reverberado.

Em suma, A Representação de Árabes e Muçulmanos na Televisão Brasileira, do historiador César Henrique de Queiroz Porto é uma obra fundamental para entendermos os múltiplos aspectos historiográficos que vão desde o modo que se dá a representação da cultura árabe na televisão/teledramaturgia até o uso dos recursos comunicativos/midiáticos como fonte de pesquisa na área da História.

\section{Referências bibliográficas}

BALBINO, Jéfferson. Teledramaturgia: o espelho da sociedade brasileira. 1. ed. São Paulo: Giostri, 2016.

PORTO, César Henrique de Queiroz. A Representação dos Árabes e Muçulmanos na Televisão Brasileira. 1. ed. Curitiba: Appris, 2020. 